\title{
Preparation of carboxymethylated polysaccharides from mycelia of Catathelasma ventricosum and their antidiabetic properties
}

\author{
Yiwen $\mathrm{Li}^{1}$, Yuxian You ${ }^{1}$, Qianqian Tang ${ }^{1}$, Siqi Zeng ${ }^{1}$, Di Chen ${ }^{1}$, Qing Zhang ${ }^{1}$, \\ Aiping Liu', Chaohui Feng ${ }^{1}$, Cheng Li ${ }^{1}$, Yuntao Liu ${ }^{1,2, a^{*}}$ \\ ${ }^{1}$ College of Food Science, Sichuan Agricultural University, Yaan 625014, China. \\ ${ }^{2}$ Animal Nutrition Institute, Sichuan Agricultural University, Chengdu 611130, China. \\ a*Iyt_taotao@163.com (corresponding author)
}

Keywords: Antioxidant, Hypoglycemic, Polysaccharide, Optimization, Carboxymethylation

\begin{abstract}
Theahoroacetic acid method under the alkaline condition is adopted to conduct carboxymethylation modification of catathelasmaventricosum polysaccharides (CVPs) to obtain carboxymethylationcatathelasmaventricosumpolysaccharides (cCVPs). In order to improve the acquiring rate (A) and degree of substitution of cCVPs, the synthetic process has been optimized. The optimal condition is: the concentration of $\mathrm{NaOH}$ is $20 \%$; the dosage of monochloro acetic acid is $3 \mathrm{~g}$; the isopropanol is $15 \mathrm{ml}$; the reaction temperature is $65^{\circ} \mathrm{C}$; the response time is $4 \mathrm{~h}$; the molecular weight is $5.0 \times 103-1.0 \times 104 \mathrm{Da}$. The final A and DS of cCVPs obtained reach $82.01 \%$ and 0.891 , respectively. Besides, the regulating level of cCVPsof the oxidative stress level within the body of mice suffering from diabetes is also studied. Experimental results suggest that carboxymethylation can significantly improve the antioxidant activity of the CVPs.
\end{abstract}

\section{Introduction}

Diabetes is a metabolic disease featuring high blood sugar, which is caused by either defects of insulin secretion or the damage of its biological function [1] or both. The long-term existing high blood sugar of patients suffering from diabetes cause a chronic damage and dysfunction of eyes, kidneys, hearts, blood vessels and nerves [2,3]. According to data issued by the World Health Organization in 2014, the number of patients suffering from diabetes has reached 347 billion [4].

The edible mushroom polysaccharide features the medicinal activity of anti-bacteria, anti-oxidation, anti-tumor and anti-diabetes [5-7]. After carboxymethlation of polysaccharides, the biological activity of polysaccharides can be greatly increased, and the water solubility and vicidity of polysaccharides can be increased [8,9] to make it extensively used in terms of food, reagent combination and industrial raw materials [10]. Currently, CVPs are not made use of to conduct carboxymethylation research. It should be noted that molecular weight of CVPs is relatively smaller compared with that of the other fungi. The DS of the former is also higher and the biological activity of the anti-oxidation and anti-diabetes can be stronger. Therefore, the employment of cCVUPs for the animal experiments will provide new ideas and references for the chemical modification and biological activity of polysaccharides.

\section{Materials and methods}

Chemicals. All reagents and drugs used in the experiment are above the analytical purity level. All the water used is super-pure water whose specific resistance is $18.2 \mathrm{M} \Omega \bullet \mathrm{cm}$.

Methods. Pre-treatment of samples:CVPs were collected from the pinusmassoniana forests and spruce forests in southwest China from April 2014 to October 2014. The specially-made plastic doctor blade is used to remove the mud on the surface of the fresh CVPs. (The mud cannot be washed with water; otherwise, polysaccharides on the surface might lose.) The fresh CPVs after cleaning are cut into slices. Every slice is of medium and even size. The CVP slices are put into the freezer dryer to obtain samples with a water content of lower than 5\%.

Preparation of CVPs:Please refer to research methods before the preparation of CVPs [11]. 
Carboxymethlation modification of CVPs:Dissolve CVPs of 250mg into $10 \mathrm{ml} \mathrm{NaOH}$ solution, and fully stir the mixed solution for $30 \mathrm{~min}$. Add certain amount of the mixed solution featuring chloroacetic acid and isopropanol into it. Stir it for $1 \mathrm{~h}$, and put it into the incubator to react for a period of time. Use $0.5 \mathrm{~m}$ HCL to adjust PH to the central level. After the dialysis of flowing water, mix it with $95 \%$ of ethanol solution four times larger in volume. Stir for 30min, put it in the refrigerator of $4{ }^{\circ} \mathrm{C}$ for $12 \mathrm{~h}$, centrifuge $(500 \mathrm{rpm}, 5 \mathrm{~min}$ ), give up the supernate and conduct freeze drying to obtain cCVPs [12-14].

Acid hydrolysis of CVPs:Take an appropriate amount of CVPs sample in a stoppered test tube, dissolved it in $0.1 \mathrm{~mol} / \mathrm{L}$ trifluoroacetic acid (TFA), and then hydrolyzed at $110{ }^{\circ} \mathrm{C}$ for $1 \mathrm{~h}$. Then, use the dialysis tube with a molecular cutoff size of $5.0 \times 102$ to conduct dialysis of the reaction liquid, to remove trifluoroacetic acid and other impurities, and to collect the liquid with the dialysis bag, namely CVPs hydrolysate. Except thatthe dialysis bag with a molecular cutoff size of $1.0 \times 106$ directly conducts the dialysis of CVPs, dialysis bags of other specifications conduct dialysis of the CVPs hydrolysate outside the dialysis bag last time.(Specifications of dialysis bag: $1.0 \times 10^{6}, 5.0 \times 10^{5}, 3.0 \times 10^{5}, 1.0 \times 10^{5}, 5.0 \times 10^{4}, 3.0 \times 10^{4}, 1.0 \times 10^{4}, 5.0 \times 10^{3}, 3.0 \times 10^{3}$ and 1.0 $\times 10^{3}$ ). The liquid within the dialysis bag is collected. After freezing, there are ten groups of different molecular weight range: $>1.0 \times 10^{6}, 5.0 \times 10^{5}-1.0 \times 10^{6}, 3.0 \times 10^{5}-5.0 \times 10^{5}, 1.0 \times$ $10^{5}-3.0 \times 10^{5}, 5.0 \times 10^{4}-1.0 \times 10^{5}, 3.0 \times 10^{4}-5.0 \times 10^{4}, 1.0 \times 10^{4}-3.0 \times 10^{4}, 5.0 \times 10^{3}-1.0 \times 10^{4}, 3.0$ $\times 10^{3}-5.0 \times 10^{3}$ and $\left.1.0 \times 10^{3}-3.0 \times 10^{3}\right)$. The optimum condition for the selection of every group is to conduct carboxymethylation and compare their DS and A so as to measure the biological activity of the optimal group.

Measurement of DS of cCVPs:Add 10mg of cCVPs after acid pickling into the $10 \mathrm{~mL}$ volumetric flask to prepare $1.0 \mathrm{mg} / \mathrm{mL}$ sample solution. Add $10 \mathrm{~mL}$ and $0.01 \mathrm{M}$ sodium hydroxide standard solution. Heat it to $40{ }^{\circ} \mathrm{C}$ through water bathing until when the solution becomes transparent. Cool it down to the indoor temperature level. Use $0.01 \mathrm{M}$ sodium hydroxide standard solution to define the constant volume on the scale. Use $0.01 \mathrm{M}$ hydrochloric acid to conduct back-titration of the excessive sodium hydroxide solution until the red on the phenolphthalein indicator just fades away.

The calculation formula of DS is shown below:

$$
A=1000 \times V_{0} \times C_{0}-V_{1} \times C_{1} \div m
$$

Degree of substitution:

$$
D S=0.132 A / 1-0.058 A
$$

Where:A stands for the amount of substance of $\mathrm{NaOH}$ consumed by every gram of sample: mmol;

$\mathrm{V}_{0}(\mathrm{~mL})$ stands for the volume of consumed sodium hydroxide solution;

$\mathrm{C}_{0}(\mathrm{~mol} / \mathrm{L})$ stands for the concentration of consumed $\mathrm{NaOH}$;

$\mathrm{V}_{1}(\mathrm{~mL})$ stands for the volume of consumed $\mathrm{NaOH}$ solution;

$\mathrm{C}_{1}(\mathrm{~mol} / \mathrm{L})$ stands for the concentration of the consumed hydrochloric acid solution;

$\mathrm{m}(\mathrm{g})$ stands for the mass of the carboxymethylation samples.

Measurement of the acquiring rate of cCVPs:

Below is the calculation formula for the acquiring rate [15]:

Acquiring rate=Mass of the original polysaccharides/Mass of the polysaccharides after carboxymethylation.

Infrared spectroscopic analysis : Use the potassium bromide pellet technique to measure the infrared spectroscopy of the optimal group. Fetch $0.1 \sim 0.5 \mathrm{mg}$ of dry cCVPs to mix with 10 50mg of dry potassium bromide. Under the lighting of the infrared lamp, it is put in the agate body to be evenly ground. After it is crushed by the tablet press into thin slices, Fourier transform infrared spectrometer is conducted.

Effects of cCVPs on oxidative stress of diabetes:The healthy and clean male ICR mice $(18 \pm 2 \mathrm{~g}$, 5 years old) are purchased from Shanghai Slyke Company. Feed them in the hope of adapting them to the new environment for two weeks with adequate water and basic feeds in the air-conditioned 
room staying at a constant temperature of $25^{\circ} \mathrm{C}$ and staying in brightness and darkness for $12 \mathrm{~h}[16]$, respectively.

Randomly choose 50 mice and put them on fasts for $12 \mathrm{~h}$. Inject $1 \%$ of STZ solution $(140 \mathrm{mg} / \mathrm{kg})$ in the enterocoelia of mice once. After 72 hours, the blood sample is taken from the tail end with glucometer employed to test the high blood sugar. The urine sugar test paper is employed to test the urine sugar. Choose 36 mice whose sugar blood is higher than $16.7 \mathrm{mmol} / \mathrm{L}$ as the diabetes model.

Randomly distribute mice to be tested to the following experiment groups (every six mice are put in one group and are tested for an experiment period of 30 days):

Group I: Normal mice as references;

Group II: Diabetes mice induced by STZ adopted as the negative control group (gavage of distilled water);

Group III: Mice induced by the STZ and the gibenclamide taken orally as the positive control group (the gavage amount of gibenclamide is $0.02 \mathrm{~g} / \mathrm{kg} / \mathrm{d}$ );

Group IV: Normal mice taking a high dosage of cCVPs (gavage amount: $2 \mathrm{~g} / \mathrm{kg} / \mathrm{d}$ );

Group V: Mice taking a low dosage of cCVPs and induced by STZ (gavage amount: $0.2 \mathrm{~g} / \mathrm{kg} / \mathrm{d}$ );

Group VI: Mice induced by STZ and taking a low dosage of CVPs. (gavage amount: $0.2 \mathrm{~g} / \mathrm{kg} / \mathrm{d}$ )

After feeding for 30 days, all tested mice are kept from eating anything for 12 hours. The weight and blood sugar of mice are measured. Blood sample is fetched from eyeballs of mice. The collected blood is quickly centrifuged $\left(5,000 \mathrm{rpm}, 5 \mathrm{~min}, 4^{\circ} \mathrm{C}\right)$ to obtain the serum and test the content of glucose in the serum. All mice are put to death through cervical vertebra dislocation. The livers and kidneys of mice are cut down, and put in the homogenizer to achieve homogenation (above the ice). After that, centrifuge $\left(3,000 \mathrm{rpm}, 10 \mathrm{~min}, 4{ }^{\circ} \mathrm{C}\right)$ is conducted. The supernatant liquid is used to test the level of catalase (CAT), malonaldeyde (MDA), superoxide dismutase (SOD), glutathione peroxidase (GSH-Px), Vitamin C and Vitamin E.

\section{Results and discussion}

cCVPs single-factor experiment. Influence of concentration of $\mathrm{NaOH}$ upon CVPs modification

Table 1 The concentration of $\mathrm{NaOH}$ on carboxymethylated the effects of substitution degree and yield of polysaccharides

\begin{tabular}{ccccccc}
\hline \multirow{2}{*}{ Test values } & \multicolumn{5}{c}{ The concentration of $\mathrm{NaOH}$} \\
\cline { 2 - 7 } & $5 \%$ & $10 \%$ & $15 \%$ & $20 \%$ & $25 \%$ & $30 \%$ \\
\hline DS & $0.455 \pm 0.007 \mathrm{a}$ & $0.524 \pm 0.008 \mathrm{~b}$ & $0.621 \pm 0.005 \mathrm{c}$ & $0.729 \pm 0.198 \mathrm{~d}$ & $0.650 \pm 0.136 \mathrm{c}$ & $0.619 \pm 0.006 \mathrm{c}$ \\
\hline A (\%) & $75.41 \pm 1.30 \mathrm{a}$ & $80.80 \pm 1.43 \mathrm{~b}$ & $80.22 \pm 0.26 \mathrm{~b}$ & $84.37 \pm 0.66 \mathrm{c}$ & $84.50 \pm 1.11 \mathrm{c}$ & $78.34 \pm 1.45 \mathrm{ab}$ \\
\hline
\end{tabular}

Note: Every value standard for the average value \pm standard deviation (SD) after three tests. Different letters in the same line stand for significant difference. $(P<0.05)$ A: Acquiring rate; DS: Degree of substitution

From Table 1, when the concentration of $\mathrm{NaOH}$ is $20 \%$, its DS is significantly superior to that of other groups $(\mathrm{p}<0.05)$; when the concentration of $\mathrm{NaOH}$ is $20 \%$ and $25 \%$, respectively, its $\mathrm{DS}$ is also significantly superior to that of the other groups $(\mathrm{p}<0.05)$. Therefore, in the single factor experiment as to the influence of concentration of $\mathrm{NaOH}$ on DS and A ofcCVPs, it is the best when concentration of $\mathrm{NaOH}$ is $20 \%$.

Influence of chloroacetic acid dosage on carboxymethylation modification of CVPs: 
Table 2 Chloroacetic acid dosage on the carboxymethylated the effects of substitution degree and yield of polysaccharides

\begin{tabular}{ccccccc}
\hline \multirow{2}{*}{ Test values } & \multicolumn{5}{c}{ The dosage of chloroacetic acid [g] } \\
\cline { 2 - 7 } & 1.5 & 2 & 2.5 & 3 & 3.5 & 4 \\
\hline DS & $0.443 \pm 0.008 \mathrm{a}$ & $0.522 \pm 0.014 \mathrm{~b}$ & $0.632 \pm 0.005 \mathrm{c}$ & $0.732 \pm 0.013 \mathrm{~d}$ & $0.514 \pm 0.009 \mathrm{~b}$ & $0.462 \pm 0.015 \mathrm{a}$ \\
\hline A (\%) & $82.22 \pm 2.13 \mathrm{~b}$ & $82.43 \pm 1.28 \mathrm{~b}$ & $83.37 \pm 0.87 \mathrm{c}$ & $84.38 \pm 0.92 \mathrm{~d}$ & $83.98 \pm 2.13 \mathrm{~cd}$ & $73.48 \pm 1.78 \mathrm{a}$
\end{tabular}

Note: Every value standard for the average value \pm standard deviation (SD) after three tests. Different letters in the same line stand for significant difference. $(P<0.05)$ A: Acquiring rate; DS: Degree of substitution

From Table 2, it can be seen that, when the chloroacetic acid dosage is $3 \mathrm{~g}$, its A is significantly superior to that of the other groups $(p<0.05)$. When the chloroacetic acid dosage is $3 \mathrm{~g}$ and $3.5 \mathrm{~g}$, its $\mathrm{A}$ is significantly superior to that of the other groups $(p<0.05)$. Therefore, in the single factor experiment as to the influence of chloroacetic acid dosage on A and DS of cCVPs, it is the best when the chloroacetic acid dosage is $3 \mathrm{~g}$.

Influence of reaction temperature on carboxymethylation modification of CVPs:

Table 3 Reaction temperature on the carboxymethylated the effects of substitution degree and yield of polysaccharides

\begin{tabular}{ccccccc}
\hline \multirow{2}{*}{ Test values } & \multicolumn{5}{c}{ Reaction temperature $\left[{ }^{\circ} \mathrm{C}\right]$} \\
\cline { 2 - 7 } & 50 & 55 & 60 & 65 & 70 & 75 \\
\hline DS & $0.247 \pm 0.004 \mathrm{a}$ & $0.428 \pm 0.007 \mathrm{~b}$ & $0.523 \pm 0.015 \mathrm{c}$ & $0.732 \pm 0.011 \mathrm{e}$ & $0.732 \pm 0.004 \mathrm{e}$ & $0.602 \pm 0.007 \mathrm{~d}$ \\
\hline A (\%) & $84.14 \pm 3.15 \mathrm{~d}$ & $83.28 \pm 2.44 \mathrm{c}$ & $83.16 \pm 0.74 \mathrm{c}$ & $83.94 \pm 1.37 \mathrm{~cd}$ & $76.48 \pm 0.87 \mathrm{~b}$ & $68.37 \pm 1.48 \mathrm{a}$
\end{tabular}

Note: Every value standard for the average value \pm standard deviation (SD) after three tests. Different letters in the same line stand for significant difference. $(P<0.05)$ A: Acquiring rate; DS: Degree of substitution

From Table 3, it can be seen that: when the reaction temperature is $65^{\circ} \mathrm{C}$ and $70^{\circ} \mathrm{C}$, its $\mathrm{DS}$ is superior to that of the other groups $(\mathrm{p}<0.05)$; when the reaction temperature is $50^{\circ} \mathrm{C}$ and $65^{\circ} \mathrm{C}$, its $\mathrm{A}$ is superior to that of the other groups $(p<0.05)$. Therefore, in the single factor experiment as to the influence of the reaction temperature on DS and A of cCVPs, it is the best when the reaction temperature is $65^{\circ} \mathrm{C}$.

Influenceof the reaction time on carboxymethylation of CVPs:

Table 4 The reaction time of carboxymethylated the effects of substitution degree and yield of polysaccharides

\begin{tabular}{ccccccc}
\hline \multirow{2}{*}{ Test values } & \multicolumn{5}{c}{ The reaction time $[\mathrm{h}]$} \\
\cline { 2 - 7 } & 1 & 2 & 3 & 4 & 5 & 6 \\
\hline DS & $0.563 \pm 0.013 \mathrm{a}$ & $0.627 \pm 0.004 \mathrm{~b}$ & $0.684 \pm 0.014 \mathrm{bc}$ & $0.728 \pm 0.007 \mathrm{c}$ & $0.624 \pm 0.008 \mathrm{~b}$ & $0.587 \pm 0.012 \mathrm{a}$ \\
\hline A (\%) & $82.74 \pm 0.93 \mathrm{c}$ & $86.85 \pm 0.72 \mathrm{~d}$ & $82.32 \pm 1.43 \mathrm{c}$ & $84.42 \pm 3.17 \mathrm{~cd}$ & $72.43 \pm 2.56 \mathrm{a}$ & $71.52 \pm 0.71 \mathrm{a}$ \\
\hline
\end{tabular}

Note: Every value standard for the average value \pm standard deviation (SD) after three tests. Different letters in the same line stand for significant difference. $(P<0.05)$ A: Acquiring rate; DS: Degree of substitution 
From Table 4 , it can be seen that its DS is significantly superior to that of the other groups $(\mathrm{p}<0.05)$ when the reaction temperature is $3 \mathrm{~h}$ AND $4 \mathrm{H}$; when the reaction time is $2 \mathrm{~h}$ and $4 \mathrm{~h}$, it's a is significantlysuperior to that of the other groups. $(p<0.05)$ Therefore, in the single factor experiment as to the influence of reaction time on DS and A ofcCVPs, it is the best when the reaction temperature is $4 \mathrm{~h}$.

Influence of molecular weight on carboxymethylation of CVPs under the ideal conditions.Carboxymethylation modification of CVPs of different molecular weights

Table 5 Molecular weight of polysaccharides carboxymethylated the effects of substitution degree and yield

\begin{tabular}{ccc}
\hline The molecular weigh CVPs & DS & A \\
\hline Hydrolysis of CVPs & $0.723 \pm 0.006$ & $66.54 \pm 1.85$ \\
\hline$>1.0 \times 10^{6}$ & $0.342 \pm 0.008$ & $87.74 \pm 0.94$ \\
\hline $5.0 \times 10^{5}-1.0 \times 10^{6}$ & $0.389 \pm 0.021$ & $84.26 \pm 2.43$ \\
\hline $3.0 \times 10^{5}-5.0 \times 10^{5}$ & $0.453 \pm 0.003$ & $74.37 \pm 1.47$ \\
\hline $1.0 \times 10^{5}-3.0 \times 10^{5}$ & $0.542 \pm 0.007$ & $71.47 \pm 0.73$ \\
\hline $5.0 \times 10^{4}-1.0 \times 10^{5}$ & $0.596 \pm 0.013$ & $65.27 \pm 3.74$ \\
\hline $3.0 \times 10^{4}-5.0 \times 10^{4}$ & $0.632 \pm 0.012$ & $61.34 \pm 0.87$ \\
\hline $1.0 \times 10^{4}-3.0 \times 10^{4}$ & $0.762 \pm 0.009$ & $54.73 \pm 1.93$ \\
\hline $5.0 \times 10^{3}-1.0 \times 10^{4}$ & $0.891 \pm 0.002$ & $51.83 \pm 3.74$ \\
\hline $3.0 \times 10^{3}-5.0 \times 10^{3}$ & $0.902 \pm 0.004$ & $38.53 \pm 2.65$ \\
\hline $1.0 \times 10^{3}-3.0 \times 10^{3}$ & $0.923 \pm 0.011$ & $34.73 \pm 1.63$ \\
\hline
\end{tabular}

Note: Every value standard for the average value \pm standard deviation (SD) after three tests. Different letters in the same line stand for significant difference. $(p<0.05)$ A: Acquiring rate; DS: Degree of substitution

From Table 5, it can be seen that the DS of three groups, whose molecular weight of polysaccharides is $5.0 \times 10^{3}-1.0 \times 10^{4}, 3.0 \times 10^{3}-5.0 \times 10^{3}$ and $1.0 \times 10^{3}-3.0 \times 10^{3}$, is obviously lower than that of the rest. $(p<0.05)$ Therefore, the optimal molecular weight group is polysaccharide with the molecular weight of $5.0 \times 10^{3}-1.0 \times 10^{4}$. The group is adopted for the infrared spectroscopic analysis and the animal experiment.

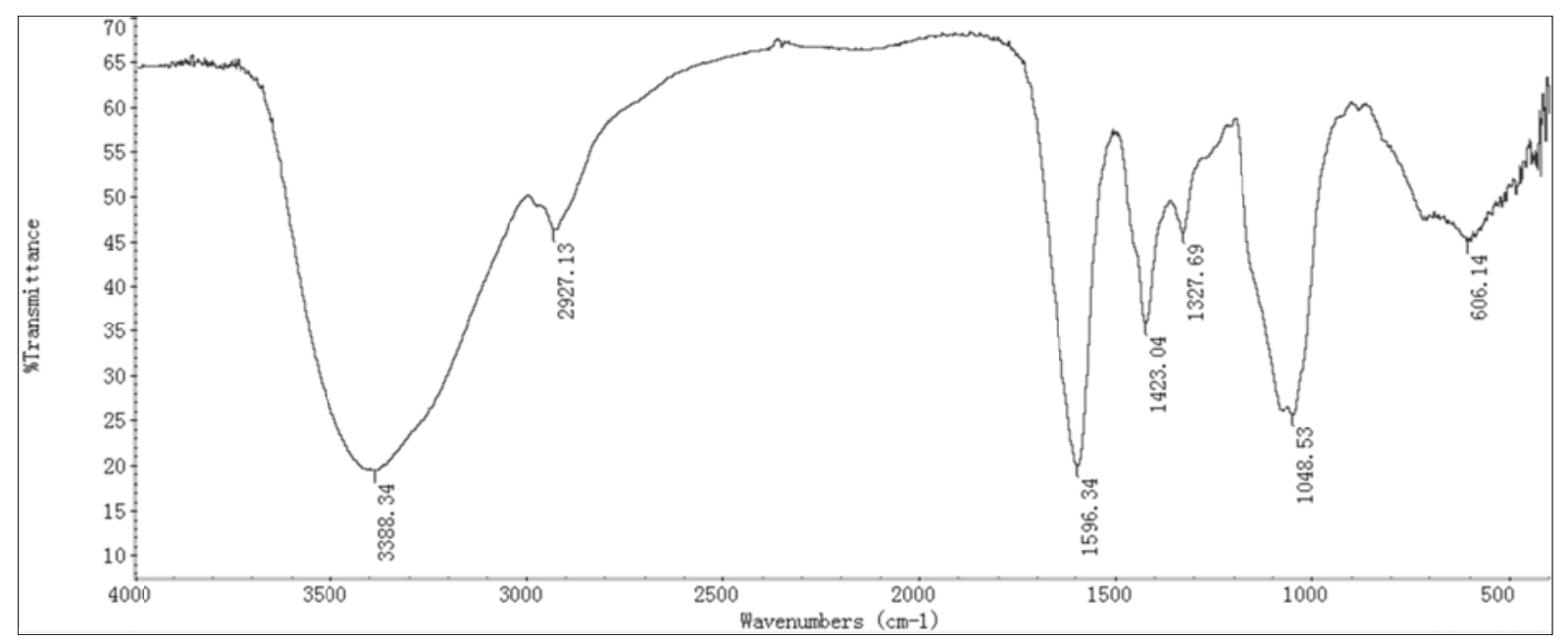

Fig. 1 Infrared spectrogram of CVPs

From Fig. 1, it can be seen that there is a characteristic absorption peak of COOC at 1596, 1423 and $1327 \mathrm{~cm}-1$. Among them, the peak at $1596 \mathrm{~cm}-1$ is an absorption peak and strong peak featuring 
C-O symmetric and asymmetric stretching vibration. At $1423 \mathrm{~cm}-1$ and $1327 \mathrm{~cm}-1$, the two peaks are moderately strong peaks. This suggests that CVPs have been actually carboxymethylated into cCVPs.

Measurement of physical signs.Influence of cCVPs on weight and blood sugar of diabetes mice

Table 6 cCVPs's influence on diabetes mice body weight, blood sugar

\begin{tabular}{lcccc}
\hline \multirow{2}{*}{ Group } & \multicolumn{2}{c}{ weight $[\mathrm{g}]$} & \multicolumn{2}{c}{ Blood glucose levels $(\mathrm{mmol} / \mathrm{L})$} \\
\cline { 2 - 5 } & $\begin{array}{c}\text { Before } \\
\text { experiment }\end{array}$ & $\begin{array}{c}\text { After } \\
\text { experiment }\end{array}$ & $\begin{array}{c}\text { Before } \\
\text { experiment }\end{array}$ & $\begin{array}{c}\text { After } \\
\text { experiment }\end{array}$ \\
\hline I (Normal) & $30.8 \pm 2.1 \mathrm{a}$ & $37.5 \pm 1.0 \mathrm{a}$ & $5.8 \pm 0.4 \mathrm{a}$ & $5.5 \pm 0.3 \mathrm{a}$ \\
II (Negative control) & $22.7 \pm 1.9 \mathrm{~b}$ & $26.3 \pm 1.0 \mathrm{~b}$ & $22.3 \pm 0.9 \mathrm{~b}$ & $22.8 \pm 1.2 \mathrm{~b}$ \\
III (Positive control) & $23.0 \pm 1.4 \mathrm{~b}$ & $33.2 \pm 0.9 \mathrm{~b}$ & $23.7 \pm 0.6 \mathrm{~b}$ & $8.9 \pm 0.8 \mathrm{c}$ \\
IV (Normal $+\mathrm{cCVPs}^{\mathrm{H}}$ ) & $32.9 \pm 0.6 \mathrm{a}$ & $37.4 \pm 0.5 \mathrm{a}$ & $5.9 \pm 0.3 \mathrm{a}$ & $5.8 \pm 0.5 \mathrm{a}$ \\
V (Diabetes $+\mathrm{cCVPs})$ & $23.5 \pm 1.0 \mathrm{~b}$ & $30.6 \pm 1.0 \mathrm{~d}$ & $21.5 \pm 1.0 \mathrm{~b}$ & $8.8 \pm 0.6 \mathrm{c}$ \\
VI (Diabetes + CVPs) & $23.7 \pm 0.7 \mathrm{~b}$ & $27.8 \pm 0.5 \mathrm{~b}$ & $22.8 \pm 1.1 \mathrm{~b}$ & $13.9 \pm 0.6 \mathrm{~d}$ \\
\hline
\end{tabular}

Note: Every value standard for the average value \pm standard deviation (SD) after three tests. Different letters in the same line stand for significant difference $(p<0.05)$. cCVPs: carboxymethylation catathelasma ventricosum polysaccharides; CVPs: catathelasma ventricosum polysaccharides; ${ }^{\mathrm{H}}$ : high dosage.

From Table 6, it can be seen that the weight of diabetes mice (in Group II, Group III, Group V and Group VI) before the experiment is lower than that of normal mice (in Group I and Group IV), and that the blood sugar of the former is significantly higher than that of the latter. $(p<0.05)$ After drugs are taken continuously for 30 days, blood sugar of diabetes mice in Group V and Group VI is significantly lower than that of the negative control group without taking any drugs. $(p<0.05)$ This suggests that CVPs and cCVPshascetain anti-diabetes activity. The weight and blood sugar indexes of mice taking cCVPs (in Group V) are obviously significantly superior to that of mice taking CVPs. This suggests CVPs can significantly improve the antidiabetic activity of polysaccharides after carboxymethylation. Weight and sugar blood indexes of normal mice show no abnormalities after taking cCVPs for 30 days at a dosage of $2 \mathrm{~g} / \mathrm{kg} / \mathrm{d}$. Besides, the function of cCVPs in reducing sugar blood is relatively lower than that of the positive control group.

Influence of cCVPs on oxidative stress within the liver of diabetes mice:

Table 7 cCVPs effects on diabetes mice oxidative stress in the liver

\begin{tabular}{ccccccc}
\hline Group & I (Normal) & $\begin{array}{c}\text { II (Negative } \\
\text { control) }\end{array}$ & $\begin{array}{c}\text { III (Positive } \\
\text { control) }\end{array}$ & $\begin{array}{l}\text { IV (Normal } \\
\left.+ \text { cCVPs }^{\mathrm{H}}\right)\end{array}$ & $\begin{array}{c}\text { V (Diabetes } \\
+\mathrm{cCVPs})\end{array}$ & $\begin{array}{c}\text { VI (Diabetes } \\
+ \text { CVPs) }\end{array}$ \\
\hline GSH-Px & $677.5 \pm 20.0 \mathrm{a}$ & $383.2 \pm 21.0 \mathrm{~b}$ & $378.7 \pm 15.9 \mathrm{~b}$ & $743.8 \pm 20.6 \mathrm{c}$ & $702.1 \pm 17.0 \mathrm{ac}$ & $619.4 \pm 18.0 \mathrm{~d}$ \\
SOD & $384.7 \pm 9.6 \mathrm{a}$ & $254.8 \pm 9.3 \mathrm{~b}$ & $227.4 \pm 12.6 \mathrm{~b}$ & $382.6 \pm 12.0 \mathrm{a}$ & $367.2 \pm 14.1 \mathrm{a}$ & $308.5 \pm 15.1 \mathrm{c}$ \\
CAT & $106.5 \pm 3.7 \mathrm{a}$ & $55.0 \pm 4.0 \mathrm{~b}$ & $64.8 \pm 3.1 \mathrm{~b}$ & $122.5 \pm 2.8 \mathrm{c}$ & $92.6 \pm 4.2 \mathrm{~d}$ & $84.7 \pm 4.8 \mathrm{~d}$ \\
MDA & $2.6 \pm 0.3 \mathrm{a}$ & $7.5 \pm 0.4 \mathrm{~b}$ & $8.8 \pm 0.2 \mathrm{c}$ & $3.2 \pm 0.2 \mathrm{a}$ & $3.8 \pm 0.4 \mathrm{a}$ & $4.4 \pm 0.5 \mathrm{ad}$ \\
$\mathrm{V}_{\mathrm{C}}$ & $6.3 \pm 0.6 \mathrm{a}$ & $1.7 \pm 0.4 \mathrm{~b}$ & $2.5 \pm 0.5 \mathrm{~b}$ & $6.6 \pm 1.4 \mathrm{a}$ & $3.6 \pm 0.6 \mathrm{~b}$ & $3.2 \pm 0.4 \mathrm{~b}$ \\
$\mathrm{~V}_{\mathrm{E}}$ & $34.5 \pm 1.9 \mathrm{a}$ & $12.8 \pm 1.3 \mathrm{~b}$ & $10.5 \pm 0.8 \mathrm{~b}$ & $36.7 \pm 1.5 \mathrm{a}$ & $17.9 \pm 1.6 \mathrm{c}$ & $18.7 \pm 1.2 \mathrm{c}$ \\
\hline
\end{tabular}

Note: Every value stands for "mean \pm SnD" of tree tests. Different letters in the same line show significant difference $(p<0.05)$; CVPs: catathelasma ventricosum polysaccharides; cCVPs: carboxymethylation catathelasma ventricosum polysaccharides; ${ }^{\mathrm{H}}$ : High dose; GSH-Px: Glutathione peroxidase(U/mg protein); SOD: Superoxide dismutase(U/mg protein); CAT: catalase(U/mg protein); MDA: malonaldehyde (nmol/mg protein); $\mathrm{V}_{\mathrm{C}}$ : Vitamin $\mathrm{C}\left(\mu \mathrm{g} / \mathrm{mg}\right.$ protein); $\mathrm{V}_{\mathrm{E}}$ : Vitamine $\mathrm{E}(\mu \mathrm{g} / \mathrm{g}$ tissue). 
From Table 7, it can be seen that the anti-oxygen level within the liver of normal mice (in Group I and Group IV) is obviously higher than that of diabetes mice (in Group II, Group III, Group V and Group VI), The MDA content (index of the oxidation of the reaction body) of the former is lower than that of diabetes mice. $(p<0.05)$ The anti-oxygen level within the liver of diabetes mice in Group $\mathrm{V}$ and Group VI after taking drugs for 30 days continuously is obviously higher than that of the negative control group taking none drugs. Besides, the MDA content of the former is obviously lower than that of the latter. $(\mathrm{p}<0.05)$ The anti-oxygen level and the MDA content of diabetes mice in Group V taking cCVPs are obviously superior to those of diabetes mice taking CVPs in Group VI. Among them, the GSH-Px and SOD of liver of diabetes mice in Group V has reached the normal level. This suggests that CVPs and cCVPs have certain anti-oxidant activity. Carboxymethylation can significantly improve the anti-oxidant activity of CVPs. After normal mice takecCVPs at a dosage of $2 \mathrm{~g} / \mathrm{kg} / \mathrm{d}$ for 30 days consecutively, their anti-oxidant indexes are all maintained at a normal level. Besides, the anti-oxidase level is significantly higher than that of the normal group. This proves that cCVPs has a strong anti-oxidant activity and is relatively safe.

\section{Acknowledgements}

This work was supported by Scientific Research Foundation of Sichuan Agricultural University (No. 06021400) and The National Natural Science Foundation of China (No. 31501550) .

\section{References}

[1] American Diabetes Association, Standards of medical care in diabetes. Diabetes Care. (2011) 34:S11-S61.

[2] P.M. Kidd, The use of mushroom Glucans and proteoglycans in cancer treatment, Cryptogamie Mycologie. 5(2000)4-27.

[3] A. Misra, M.S. Lalan and V.K. Singh, Role of natural polysaccharides in treatment and control of diabetes, Recent Progress in Medicinal Plants. 25(2009)347-373.

[4] http://www.who.int/mediacentre/factsheets/fs312/en/, 2011.

[5] F.M.N.A. Aida, M. Yazid and A.G. Maaruf, Mushroom as a potential source of prebiotics, Trend in Food Science and Technology. 20(2009)567-575.

[6] L.Q. Yang and L.M. Zhang, Chenical structural and chain conformational characterization of some bioactive polysaccharides isolated from natural sources, Carbohydrate Polymers. 76(2009)349-361.

[7] J. Hamuro, Y. Tamashita, Y. Ohaska, Y.Y. Maeda and G. Chihara, Carboxymethylpachymaran, a new water soluble polysaccharide with marked antitumour activity, Nature. 233(1917)486-488.

[8] J. Wang, L. Zhang, Y. Yu and P.C.K. Cheung, Enhancement of antitumour activities in sulfated and carboxymethylated polysaccharides of Ganodermalucidum, Journal of Agricultural and Food Chemistry. 57(2009)10565-10572.

[9] J. Xu, W. Liu, W. Yao, X Pang, D. Yin and X Gao, Carboxymethylation of a polysaccharide extracted from Ganodermalucidum enhances its antioxidant activities in vitro, Carbohydrate Polymers. 78(2009)227-234.

[10] C. Tranquilan-Aranilla, N. Nagasawa, A. Bayquen and R. Dela, Synthesis and characterization of carboxymethyl derivatives of kappa-carrageenan, Carbohydrate Polymers. 78(2012)1810-1816.

[11] Y.T. Liu, J. Sun and S.Q. Rao, Antihyperglycemic, antihyperlipidemic and antioxidant activities of polysaccharides from Catathelasma ventricosum in streptozotocin-induced diabetic mice, Food and Chemical Toxicology. 57(2013)39-45.

[12] Y. Francini, Kagimuraa, A. MárioAntônio, D. Cunhaa and V. Thais, Carboxymethylation of $(1 \rightarrow 6)-\beta$-glucan (lasiodiplodan):Preparation, characterization and antioxidant evaluation, Carbohydrate Polymers. 127(2015)390-399.

[13] X. Sun, X Jin, W Pan and J Wang, Syntheses of new rare earth complexes with carboxymethylated polysaccharides and evaluation of their in vitro antifungal activities, Carbohydrate Polymers. 113(2014)194-199. 
[14] Y Tao, R Zhang, W Yang, H Lin, H Yang and Q Zhao, Carboxymethylatedhyperbranched polysaccharide:Synthesis, solution properties, and fabrication of hydrogel, Carbohydrate Polymers. 128(2015)170-187.

[15] L. Jiang, S Nie, H Zhou, D Huang and $M$ Xie, Carboxymethylation enhances the maturation-inducing activity in dendritic cells of polysaccharide from the seeds of Plantago asiatica L, International Immunopharmacology. 22(2014)324-331.

[16] P. Poucheret, F. Fons and S. Rapior, Biological and pharmacological activity of higher fungi:20-year retrospective analysis, Cryptogamie Mycologie. 27(2006)311-333. 